\title{
Do economic policy uncertainty and financial development influence the renewable energy consumption levels in China?
}

\author{
Wang Lei ${ }^{1} \cdot$ Lihan Liu $^{2} \cdot$ Muhammad Hafeez $^{2,3} \cdot$ Sidra Sohail $^{4}$ \\ Received: 12 May 2021 / Accepted: 23 August 2021 / Published online: 4 September 2021 \\ (C) The Author(s), under exclusive licence to Springer-Verlag GmbH Germany, part of Springer Nature 2021
}

\begin{abstract}
Last few decades, several economic uncertainty challenges have emerged in the energy market. This study newly contributes to existing research by inspecting the asymmetric effect of economic policy uncertainty and financial development on renewable energy consumption in China. We employ a nonlinear ARDL approach by using a time-series dataset spanning from 1990 to 2019. Our symmetric model shows that economic policy uncertainty matters in the short run, as it increases renewable energy consumption while exhibiting a negative impact on renewable energy in long run in China. Our asymmetric results in the short and long run have deviated from the symmetric results. Our asymmetric results of the short and long run are similar in direction but different in magnitude. The results show that positive change in economic policy uncertainty has increased $3.216 \%$ and negative change in economic policy uncertainty has decreased $1.461 \%$ in renewable energy consumption in long run in China. Financial development does not matter in renewable energy consumption in China. Based on these outcomes, we can draw some robust economic policies in China as well as for other pollutant economies. Policymakers should be made economic policies more predictable in the modern era.
\end{abstract}

Keywords Economic policy uncertainties $\cdot$ Financial development $\cdot$ Renewable energy consumption $\cdot$ China $\cdot$ NARDL

\section{Introduction}

Policymakers and academia are equally exposed an endless research interest in economic policy uncertainty and its effect

Responsible Editor: Ilhan Ozturk

Lihan Liu

liulihan@bwu.edu.cn

Wang Lei

wangleisss@guet.edu.cn

Muhammad Hafeez

hafeez_86@hotmail.com

Sidra Sohail

sidrasohail_14@pide.edu.pk

1 Business School, Guilin University of Electronic Technology, Guilin, Guangxi, China

2 Beijing Wuzi University, Beijing, China

3 Faculty of Management \& Administrative Sciences (FMAS), University of Sialkot, Sialkot, Pakistan

4 Pakistan Institute of Development Economics (PIDE), Islamabad, Pakistan on energy consumption as well as economic activities. In this respect, fiscal and monetary concerns have often been linked with recessions from earlier to the present (Bernanke 1983; Pindyck and Rubinfeld, 1991; Bloom 2009; Lin et al 2020). More recently, economic policy uncertainty indexes were established by Baker et al. (2013), which is most commonly used in energy and environmental economic research in the last decades (Adams et al. 2020 and Pirgaip and Dinçergök, 2020). However, an articulate body of linked empirical research shows that economic policy uncertainty has adverse impacts on economic activity (Hu et al. 2019 and Adedoyin and Zakari 2020).

Economic activity, as returned in economic growth, is anticipated to be the consequence of energy consumption particularly when the economy heavily relies on energy due to the considered large size of the economy. But queries remain, what happens to renewable energy consumption under ambiguous economic policy conditions? Should a state encourage renewable energy policies to release uncertainty in economic policy in the economy? Present empirical literature results from its origins start from the pioneering study of Hamilton (1983), who argued that economic policy uncertainty and consumption of energy may be deliberated as closely attached 
through variations in energy prices generated by supply and demand shocks in the market as well as negative expectations on economic activities, which may stimulus firm and consumer decision-making on energy utilization ( $\mathrm{Li}$ et al. 2019; Rehman and Deyuan 2018; Hailemariam et al. 2019).

Clean energy is the new supportive industry of economic development. In current years, the economic environment is a changeable and complex phenomenon, and to discuss clean energy consumption, specifically, renewable energymomentum is a significant component of economic growth. The modification of economic policy will ultimately be influenced in enterprises' clean investment choices and they further affect the consumption of conventional and renewable energy. The literature also infers that economic policy uncertainty, conventional energy, and renewable energy are interlinked with each other (Pirgaip and Dinçergök, 2020). For instance, Gong et al., 2012) consider the level of clean energy investment modifications with the change of monetary policy. In literature, a loose monetary policy can encourage clean energy enterprises' investment and a tight monetary policy can hinder clean energy enterprises' investment in the economy. Gustafsson and Shi (2003) clue the change of fiscal and monetary policies that can influence clean energy enterprises' investment; moreover, the stability of economic policy also meaningfully increases enterprises' risks and influences their investment behavior by making the expectations (Omri \& Nguyen 2014). Bernanke (1983) embraces that the time, direction, and content of economic policy change the economic decision-making behaviors, which makes consumers and enterprises more careful in uncertain periods. Therefore, economic policy uncertainty influences the behavior of renewable energy enterprises. This means that economic policy uncertainty is affecting the supply and demand side of renewable energy (Sharif et al. 2020). Economic policy uncertainty indicates that it is a state whereby an economic theme cannot forecast precisely when, whether, and how the government authority will change present economic policies.

Nowadays, China is at the phase of the "New Normal Economy," the emphasis on economic real alteration in the economy, and energy enterprises will be playing a key role in this process. It is famous that "China's Thirteenth Five-Year Plan for Renewable Energy Development" transforms conventional energy into a renewable energy system and lastly they will be entered into the new era of sustainable clean renewable energy. The impacts of economic policy uncertainty on outdated and renewable energy may also be different in factors. Therefore, economic policy uncertainty is one of the common factors that affect traditional and renewable energy consumption positively as well as negatively.

One of the key objectives of China is to increase the renewable energy consumption level that brings financial development. Sadorsky (2011) noted that level of financial development can effect energy consumption through three different channels: direct effect, wealth effect, and business effect. The direct effect refers that customers directly leads to an increase in the demand for renewable energy consumption by using efficient financial intermediation. The business effect is also effect renewable energy consumption, which offers firms better access to financial capital. The business channel is also provided less costly financial capital, in return to increase the consumption of renewable energy (Baloch et al. 2021). The wealth effect is formed by the households and firms have in the developed stock market (Anton \& Nucu, 2020).

In common, linking with the present research, this study has done the next new aspect of work. First, earlier empirical studies pay more devotion to the consumption behavior of energy consumers under environmental uncertainty, but the literature on renewable energy enterprises is quite scarce (Murshed, 2020a, band Murshed et al. 2020). Also, current studies mostly focus on the effect of macro-policies on traditional energy consumption, while this study emphasizes economic policy ambiguity rather than the role of a specific or single policy, for instance, monetary and fiscal policy. The study benefits explain the inner mechanism of economic policy uncertainty influencing renewable energy-momentum in China. The past study is to assess the symmetric behavior of economic policy uncertainty on renewable energy consumption (Liu et al. 2020 and Pirgaip and Dinçergök, 2020) that give the bias results in China and G7 economies. Shafiullah et al. (2021) reported that economic policy uncertainty has a negative impact on renewable energy consumptions in the USA. In line, Liu et al. (2020) and Pirgaip and Dinçergök (2020) confess that economic policy uncertainty has a nonlinearity influenced on renewable energy consumption but could not measure the nonlinear relationship econometrically. Our empirical outcome approach resolves the problem of biasness and misleading inferences by giving the asymmetric estimates of economic policy uncertainty in the context of renewable energy consumption. This study is different from past literature due to the nonlinearity objective. In crux, our asymmetric methodology permits us to address the impact of shocks in economic policy uncertainty in a separate manner. There are increasing numbers of studies on economic policy uncertainty but it does not assess the influence of policy uncertainty on renewable energy consumption. This study fills the gap in previous empirical studies.

Furthermore, this is a pioneer study in the case of China around the globe that pinpoints the nonlinear links among the economic policy uncertainty and renewable energy consumption and gives a new background in renewable energy consumption. Our study period spans from 1990 to 2019, has a yearly frequency, and focuses on China. Our analysis focuses on China's economy, because this economy representing a large one in the world, China accounted for $24 \%$ of global 
energy consumption, the largest producer of $\mathrm{CO} 2$ emissions in the world (World Bank 2019). The empirical findings of this study offer a better understanding and important information and evidence to academic researchers, individuals, economists, and policymakers. This study offers important economic implications to policymakers, government authorities, and environmentalists for assuring environmental conservation. Our study is more helpful for the economic and environmental performance of the pollutant economies which is facing environmental and energy challenges. To our information, our research work is unique that concerns economic policy uncertainty in the context of renewable energy consumption.

The remaining sections of the study are organized as follows. "Literature review" section reviews the literature and "Model, methodology, and data" section highlights the data, model, and empirical methodology. The empirical results are reported in the "Results and discussion" section. Finally, "Conclusion and policy implication" section provides concluding remarks and offers policy implications.

\section{Literature review}

Nowadays, energy users are considering the usage of renewable energy consumption such as hydropower, wind, and solar. The respective economic policy uncertainties, like oil prices, exchange rates, bond markets, and stock markets, accelerate the need for the transition of energy. The economic policy uncertainties are considered vital factors for the enlargement of renewable energy consumption. The economic policy triggers the clean energy sector development at its initial stages through preferential tax policies, transfer payments, augmented depreciation, investment credits, and subsidies from government. But there is lack of consensus among environmentalists and economists regarding the association between renewable energy consumption and economic policy uncertainties. Thus, to shed light on the linkage between economic policy uncertainties and renewable energy consumption, there is a need to explore this area in more detail.

Kang et al. (2017) examined the effects of economic policy uncertainties and oil price shocks on clean energy. The study reports that economic policy uncertainties negatively affect renewable energy consumption, whereas demand-side oil price shock exerts a positive impact on renewable energy companies. Few studies have explored the impact of economic policy uncertainty on the stock returns of gas and oil (Kang and Ratti 2013 and Zhang et al. 2015). These studies conclude that economic policy uncertainties have a significant impact on stock returns of gas and oil. A bulk of literature is found on the issue of the economic policy uncertainty impact on energy prices (Reboredo and Wen, 2015; Pastor and Veronesi, 2012). Ma et al. (2021) reported a predictable association between economic policy uncertainty and energy prices, while Yin and
Han (2014) concluded that the dynamic association between energy prices and economic policy uncertainty changes over the passage of time. Watugala (2014) examined the effect of economic policy uncertainty on energy volatility. The study confirmed the predictability of energy future volatility by adopting such variables that demonstrate macroeconomic uncertainties.

Another imperative aspect in determining renewable energy consumption and energy prices is financial stress and uncertainty. Chen et al., 2018) explored how energy prices and future positions of financial traders changed in response of financial crises and reported that uncertainty has a significant negative impact on energy prices. Ji et al. (2018) argued that energy market is the most imperative sector whose price significantly varies in response to economic uncertainty. Several studies documented that economic policy uncertainty played vital role in determining energy prices after the incident of global financial crises. For example, Liu et al. (2018) and Joets (2015) demonstrate that uncertainty leads to volatility in energy consumption and energy prices. Consequently, the volatility in energy consumption and energy prices exert a strong influence on real economy and impede the financial market stability. The driving forces behind the energy market are diversified and complex. Energy prices cannot be fully elucidated by the demand and supply framework. Mellios et al. (2016) argued that an increase in uncertainty in the energy market has reduced the dynamics of energy prices. Therefore, uncertainty has become more imperative determinant that affects both energy market risk and energy prices volatility. Hence, the identification of most relevant measures of uncertainty has gained considerable attention of researchers (Wu et al. 2021 and Baker et al. 2016). Bloom, 2009) highlighted that respective volatilities of GDP growth, exchange rate markets, bonds markets, and stock markets rise abruptly during the phase of recessions. The study concluded that every macroeconomic determinant of uncertainty behaves counter-cyclically as the volatility of these determinants rises when the economy slows down. Chen and Kettunen (2017) examined the effect of economic policy uncertainty on carbon policy of firms and concluded that it is more optimal for firms to invest in renewable energy technologies in order to avoid climatic risk.

Lundgren et al. (2018) explored the association between renewable energy consumption and uncertainty instigated by the economic policy and financial market. The study reported the significance of uncertainty concerning the volatility and returns of clean energy consumption. Ferrer et al. (2018) further investigated the connectedness between policy uncertainty and renewable energy consumption using a dynamic method. Zhang et al. (2019) compared the effect of uncertainty from the economic policy, oil market, and financial market on renewable energy consumption. The study also reported that economic policy uncertainty is more imperative 
in the framework of renewable energy consumption stocks than conventional energy consumption stocks.

Renewable energy consumption endorses energy security, while worldwide use of renewable energy consumption is low as compared to other sources of energy (Bourcet, 2020 and Joshua \& Bekun, 2020). Several variables, such as government ideology, institutional quality, energy prices, financial development, technological innovation, population growth, pollution emissions, trade openness, and GDP growth, has been incorporated to investigate the impact of renewable energy consumption (Ergun et al. 2019; Murshed, 2020a, b; and Murshed \& Alam, 2021). However, not much attention is delivered to explore the impact of economic policy uncertainty on renewable energy consumption. Economic policy uncertainty most specifically captures the impact of uncertainties in regulatory and political structures (Baker et al. 2016). AlThaqeb and Algharabali (2019) highlighted that the past decade has witnessed hasty economic and political uncertainties. The most recent economic policy uncertainty is the COVID19 pandemic that has also increased worldwide uncertainties related to bank stability, cash flow of firms, households saving and consumption decision, investment, energy stock returns, financial development, economic growth, and renewable energy consumption (Iyke 2020; Appiah-Otoo 2020). What role economic policy uncertainty plays in effecting renewable energy consumption is still unexplored. Balcilar et al. (2019) stated that economic policy uncertainties hinder renewable energy consumption. The study also declared that due to economic policy uncertainties, policymakers become reluctant to adopt renewable energy consumption-related policies.

Although several aspects of economic policy uncertainty have been unexplored, little research has been done to explore the effective impact of economic policy uncertainty on renewable energy consumption. In order to fill this gap, the present study is determined to investigate the impact of economic policy uncertainties on renewable energy consumption in China.

\section{Model, methodology, and data}

Several empirical studies in the past have inspected the economic policy uncertainty-energy consumption nexus (Adedoyin and Zakari, 2020and Pirgaip and Dinçergök, 2020). Several studies have been conducted on economic policy uncertainty-CO2 emissions nexus (Abbasi and Adedoyin, 2021 and $\mathrm{Yu}$ et al. 2021) and some on economic policy uncertainty-economic growth link (Bhagat et al. 2013 and Junttila \& Vataja, 2018). However, this study differs by familiarizing economic policy uncertainty as a variable into a model of renewable energy consumption. The model follows the theoretical and empirical literature (Al-Thaqeb \& Algharabali 2019 and Shafiullah et al. 2021). We closely follow Al-
Thaqeb and Algharabali (2019) theoretical specifications and examining the asymmetric impact of economic policy uncertainty on renewable energy consumption. The basic form is:

$R E C_{t}=\varphi_{0}+\varphi_{1} E P U_{t}+\varphi_{2 i} X_{t}+\varepsilon_{t}$

where subscripts $t$ indicate years; $\varphi_{0}, \varphi_{1}$, and $\varphi_{2 \mathrm{i}}$ are parameters for estimation; $R E C_{t}$ denotes renewable energy consumption; $E P U_{t}$ denotes economic policy uncertainty; $X_{t}$ denotes the vector of control variables; and $\varepsilon_{t}$ is an error term, respectively. Equation (1) is supposed to depend on renewable energy consumption and foreign direct investment (FDI), economic size (ES), and financial development (FD). Similarly, increased economic policy uncertainty leads to less renewable energy consumption; we expect estimates of $\varphi_{1}$ to be negative. However, this model only provides us with the long-run results; to get the shortrun results we redefine model (1) into error correction specification as specified underneath:

$$
\begin{aligned}
\Delta R E C_{t}= & \omega_{0}+\sum_{k=1}^{n} \beta_{1 k} \Delta R E C_{t-k}+\sum_{k=0}^{n} \beta_{1 k} \Delta E P U_{t-k} \\
& +\sum_{k=0}^{n} \beta_{1 k} \Delta X_{t-k}+\omega_{1} R E C_{t-1}+\omega_{2} E P U_{t-1} \\
& +\omega_{3 i} X_{t-1}+\varepsilon_{t}
\end{aligned}
$$

The short-run impacts are revealed in form of "firstdifferenced" variables and long-run impacts are yielded by the estimates of $\omega_{2}-\omega_{3 i}$ normalized on $\omega_{1}$ in equation (2). A key assumption in equation (2) is that the effect of economic policy uncertainty on renewable energy consumption is symmetric. Al-Thaqeb and Algharabali (2019) noted that the economic policy uncertainty effects on macroeconomic factors are asymmetric because increases in economic policy uncertainty have a much more significant impact on the macroeconomic variables than do decreases in economic policy uncertainty. Thus, our research question is that does economic policy uncertainty have an asymmetric effect on renewable energy consumption in China? Therefore, we have modified equation (2) so that we can estimate the asymmetric impact effects of economic policy uncertainty on renewable energy consumption. Our model change follows the Shin et al. (2014) asymmetric approach. Regarding this approach, we must be decomposed " $E P U_{t}$ " into two time-series variables, one signifying increased economic policy uncertainty and one signifying declines in economic policy uncertainty and exposed beneath:

$$
\begin{aligned}
& E P U_{t}=\sum_{n=1}^{t} \Delta E P U^{+}{ }_{t}=\sum_{n=1}^{t} \max \left(\Delta E P U^{+}{ }_{t}, 0\right) \\
& E P U^{-}{ }_{t}=\sum_{n=1}^{t} \Delta E P{U^{-}}_{t}=\sum_{n=1}^{t} \min \left(\Delta E P U^{-}{ }_{t}, 0\right)
\end{aligned}
$$


where $E P U^{+}$, a variable, is the partial sum of positive changes in economic policy uncertainty which infers only increased economic policy uncertainty. Similarly, EPU ${ }_{t}$ is the partial sum of negative changes in economic policy uncertainty which infers only deceased economic policy uncertainty. Thus, we moving back to equations (2) to replace $E P U_{t}$ by $E P U^{+}{ }_{t}$ and $E P U_{t}$ and our extended error-correction model is as:

$$
\begin{aligned}
\Delta R E C_{t}= & \alpha_{0}+\sum_{k=1}^{n} \beta_{1 k} \Delta R E C_{t-k}+\sum_{k=0}^{n} \beta_{1 k} \Delta E P U^{+}{ }_{t-k} \\
& +\sum_{k=0}^{n} \delta_{1 k} \Delta E P U^{-}{ }_{t-k}+\sum_{k=0}^{n} \beta_{1 k} X_{t-k} \\
& +\omega_{1} R E C_{t-1}+\omega_{2} E P U^{+}{ }_{t-1}+\omega_{3} E P U^{-}{ }_{t-1} \\
& +\omega_{4 i} X_{t-1}+\varepsilon_{t}
\end{aligned}
$$

Equation (4) is known as the NARDL model proposed by Shin et al. (2014) and this is an advanced form of the linear ARDL. Therefore, nonlinear ARDL can be dealt with the estimation procedure and diagnostic test of the linear ARDL. Moreover, the cointegration test and critical values are also the same for both models. Similarly, we also estimate the symmetric causality by using the Toda and Yamamoto (1995) and asymmetric causality estimates through Hatemi- $\mathrm{j}$ (2012) tests by using the models (2) and (4) for China using aggregate-level data.

We utilized renewable energy consumption that is a ratio of overall final energy consumption and measured in quad BTU, while data is provided by energy information administration (EIA). Economic policy uncertainty is an index of China and data is available on http://www.policyuncertainty.com/. Similarly, foreign direct investment is net inflows that is $\%$ share of GDP, economic size is proxied by gross domestic product (current US\$), and financial development is measured by credit to the private sector in economy (\% of GDP). Economic size, financial development, and FDI variables are obtained from World Bank.

\section{Results and discussion}

This section computes linear ARDL model (2) and nonlinear ARDL model (4) by using the China time-series dataset over the period 1990-2019. Before the estimation, we have pilot testing for concern variables. The results of ADF and PP unit root statistics are reported in Table 1. Findings of the ADF test show that all the variables are stationary at I(1), while PP statistics show that FDI is stationary at $\mathrm{I}(0)$ and all other variables are stationary at I(1) in Table 1 . The results of unit root with structural break tests confirm in Table 1 that our variables are either $\mathrm{I}(0)$ or $\mathrm{I}(1)$. Thus, our unit root estimates are suitable for the ARDL methodology.

Table 2 reports the long-run and short-run ARDL results in the model (1) by estimating equation (2). The long-run estimates established that EPU has a negative link with renewable energy consumption at the $5 \%$ level of significance. This outcome infers that economic policy uncertainty can lead to decreased renewable energy consumption with an average value of $-4.476 \%$. This could be a consequence of using noncleaner energy consumption. This finding is consistent with the study of Lafforgue (2005), who identified a negative impact of economic policy uncertainty on renewable energy consumption. This means that renewable energy is a necessary part of energy security and becoming a less cost-competitive alternative option in economic policy uncertainty and hence reduced renewable energy consumption in China. Another reason is that renewable energy consumption provides high incentive levels; therefore, high uncertainty in economic policy negatively affects renewable energy. The decline in renewable energy consumption is due to the high uncertainty in economic policy that slows down the economic growth of China. Our finding is also consistent with Shafiullah et al. (2021), who reported the negative link between policy uncertainty and renewable energy consumption in long run.

This finding collectively underscores the economic policies that explain a notable amount of the variation of the renewable energy market in China; however, uncertainty in policies plays a negative role in clean energy consumption. The "green society" is normally cautious in management policies in energy economics, as the Chinese economy is largest pollutant in the world and implies that China has more uncertainty in economic policies. The economic policy uncertainty harms the whole economic situation and even the performance of enterprises that use renewable energy in China. This implies that, due to the economic policy uncertainty, residents and enterprises, they may choose to use traditional cheaper energy such as oil that may reduce renewable energy consumption. Meanwhile, local and international investors are not investment confidence in renewable energy consumption due to the economic policy uncertainty. Also, a large body of empirical literature also finds that the EPU has effects on renewable and non-renewable energy consumption (Sohail et al. 2021). This means that EPU overall affects the renewable energy market.

Similarly, $1 \%$ rise in economic size leads to a decrease of $13.38 \%$ in renewable energy consumption in China in long run. This reduced amount of renewable energy is quite large in China due to a reduction in economic size. However, FD indicates no link with renewable energy consumption in China. This suggests that financial development is never an indicator of renewable energy consumption in China. The long-run estimate shows that FDI has a positive effect on renewable energy consumption; this may be possible because 
Table. 1 Unit root tests

\begin{tabular}{|c|c|c|c|c|c|c|c|c|c|c|c|}
\hline & \multicolumn{3}{|c|}{ ADF test statistic } & \multicolumn{3}{|c|}{ PP test statistic } & \multicolumn{5}{|c|}{ Unit root testing with break } \\
\hline & $\mathrm{I}(0)$ & $\mathrm{I}(1)$ & Decision & $\mathrm{I}(0)$ & $\mathrm{I}(1)$ & Decision & $\mathrm{I}(0)$ & Break date & $\mathrm{I}(1)$ & Break date & Decision \\
\hline REC & 0.224 & $-3.805 * * *$ & $\mathrm{I}(1)$ & -0.213 & $-3.891 * * *$ & $\mathrm{I}(1)$ & -3.145 & 2002 & $-4.356^{*}$ & 2004 & $\mathrm{I}(1)$ \\
\hline EPU & -2.033 & $-5.645 * * *$ & $\mathrm{I}(1)$ & -1.612 & $-5.688 * * *$ & $\mathrm{I}(1)$ & -2.854 & 2000 & $-7.854 * * *$ & 2001 & $\mathrm{I}(1)$ \\
\hline ES & -0.803 & $-2.840 * *$ & $\mathrm{I}(1)$ & -0.685 & $-2.849 * *$ & $\mathrm{I}(1)$ & -3.132 & 2003 & $-4.325^{*}$ & 2011 & $\mathrm{I}(1)$ \\
\hline FD & 0.435 & $-5.527 * * *$ & $\mathrm{I}(1)$ & -0.322 & $-5.643 * * *$ & $\mathrm{I}(1)$ & $-5.022 * * *$ & 2008 & & & $\mathrm{I}(0)$ \\
\hline FDI & 1.965 & $5.786^{* * *}$ & $\mathrm{I}(1)$ & $-2.881 * *$ & & $\mathrm{I}(0)$ & -3.287 & 2011 & $-4.412 *$ & 2007 & $\mathrm{I}(1)$ \\
\hline
\end{tabular}

$*$, **, and $* * *$ reflect the $1 \%, 5 \%$, and $10 \%$ level of significance respectively

they reduce the conventional energy consumption by increasing the clean energy consumption in China by $4.571 \%$ in long run.

As for the short run, by contrast, the current values of EPU have a positive influence on renewable energy because they upsurge the consumption of renewable energy consumption by $0.950 \%$. Policy uncertainty in the economy could be a positive role in renewable energy consumption. The result is similar to the study of Liu et al. (2020), who noted that economic policy uncertainty enhanced geothermal and solar energy in China. Similarly, FDI also positively impact renewable energy consumption; it means that renewable energy consumption decreased with an average of $1.731 \%$ due to an increase in FDI. Surprisingly, economic size and financial development show no connection with renewable energy consumption in the short term.

Panel $C$ shows the diagnostic outcomes of ARDL model. $F$ test indicates that long-term equilibrium exists among the series and co-integrated in the long run. The short-run estimates of ECM show that the model is stable because it has a negative significance value of -0.553 at $5 \%$ level. While LM, BreuschPagan (BP), and RESET tests are statistically insignificant, supporting no problem of autocorrelation, model is free from heteroskedasticity problem and correctly specified. ARDL estimates are stable (S) in CUSUM and CUSUM squares statistics. Finally, ARDL model has also reported the goodness of fit because the adjusted $R^{2}$ is 0.89 .

Table 2 also displays the NARDL outcomes for model (2) and equation (4) and the long-run estimate indicates that positive change in EPU has a positive effect on renewable energy consumption, while a negative change in EPU has a negative significant effect on renewable energy consumption. Coefficients of the long run for China show that positive change in EPU has increased 3.216\% and negative change in EPU has decreased a $1.461 \%$ in renewable energy consumption. This finding is also consistent with Liu et al. (2020), who noted that economic policy uncertainty is positively affecting solar energy and geothermal energy. This also means that economic policy uncertainty is affecting the systematic risks and clean energy investment behavior of firms and also affecting the consumption side of the consumer. This also implies that asymmetric ARDL results are correct in the coefficient estimates of economic policy uncertainty in long run. Transmission channels of positive effects, such as cash flow, capital cost, real options, investors' risk perception, and financial friction, are the key responsible paths of economic policy uncertainty that is inducing enterprises' investment in renewable energy consumption and indirectly also affecting the consumption of the consumer. This is one of the possible and main factors of supply size as well as demand size. Shortly, economic policy uncertainty has reproduced the effect on the energy market. This also infers that economic policy uncertainty has a substitution effect on the consumption of renewable energy that is more in the consumption of renewable energy as compared to traditional energy consumption. Economic size, FD, and FDI results are maintained in the nonlinear ARDL model in long run. This means that economic size increase by $14.46 \%$ and FDI increase by $2.457 \%$ renewable energy consumption in China. This also infers that FDI is playing a matter in clean energy consumption in China, while the economic size is not considered renewable energy consumption.

Regarding short-run estimates, the results also display that the positive change in EPU has a significant positive impact on renewable energy consumption in China. A $1 \%$ negative change in EPU would prime to a renewable energy consumption increase of $1.914 \%$ for China. Similarly, the results also show that the negative change in EPU has a negative and significant effect on renewable energy consumption in China. A $1 \%$ negative change in EPU would central to a renewable energy consumption decrease of $-1.262 \%$ for China. While short-run estimates of control variables are improved, the findings show that economic size is positively significant and increase by $6.282 \%$ renewable energy consumption in China. Similarly, FDI is also paying a role in consumption of renewable energy and it is positively significant at $10 \%$ level in the case study of China.

Few diagnostic statistics for nonlinear ARDL model are reported in Table 2 in panel C. The statistics of $F$ test and ECM have a significance, which is a sign of co-integration existed in the asymmetric model. LM, BP, and RESET statistics are insignificant, which suggests that there are no issues of 
Table. 2 ARDL and NARDL results

\begin{tabular}{|c|c|c|c|c|c|c|}
\hline & \multicolumn{3}{|l|}{ ARDL } & \multicolumn{3}{|l|}{ NARDL } \\
\hline & Coefficient & Std. error & $t$-Statistic & Coefficient & Std. error & $t$-Statistic \\
\hline \multicolumn{7}{|c|}{ Panel B: short-run estimates } \\
\hline$\triangle E P U_{t}$ & $0.950 *$ & 0.534 & 1.779 & & & \\
\hline$\Delta E P U_{t-1}$ & -0.450 & 0.454 & -0.991 & & & \\
\hline$\triangle E P U_{t}^{+}$ & & & & $1.914 *$ & 1.070 & 1.788 \\
\hline$\triangle E P U_{t-1}^{+}$ & & & & 0.999 & 1.842 & 0.543 \\
\hline$\triangle E P U_{t-2}^{+}$ & & & & $16.58^{* *}$ & 7.536 & 2.201 \\
\hline$\triangle E P U_{t}^{-}$ & & & & $-1.262 *$ & 0.644 & 1.954 \\
\hline$\triangle E P U_{t-1}^{-}$ & & & & 1.539 & 1.386 & 1.110 \\
\hline$\triangle E P U_{t-2}^{-}$ & & & & $-3.095^{*}$ & 1.783 & -1.736 \\
\hline$\Delta E S_{t}$ & 2.665 & 6.472 & 0.412 & $6.282 * * *$ & 2.414 & 2.602 \\
\hline$\Delta E S_{t-1}$ & -8.712 & 6.547 & -1.331 & $-11.29 * * *$ & 4.079 & -2.767 \\
\hline$\Delta E S_{t-2}$ & & & & $7.902 * *$ & 3.621 & 2.105 \\
\hline$\Delta F D_{t}$ & 9.305 & 8.011 & 1.162 & 10.01 & 20.52 & 0.488 \\
\hline$\Delta F D_{t-1}$ & 1.424 & 4.084 & 0.349 & -4.322 & 2.821 & -1.532 \\
\hline$\Delta F D_{t-2}$ & $-7.952 * *$ & 3.769 & -2.110 & -9.577 & 6.016 & -1.592 \\
\hline$\Delta F D I_{t}$ & $1.713 * *$ & 0.727 & 2.356 & $2.004 *$ & 1.119 & 1.792 \\
\hline$\Delta F D I_{t-2}$ & & & & $1.186^{*}$ & 0.649 & 1.827 \\
\hline$\Delta F D I_{t-3}$ & & & & 0.632 & 0.519 & 1.219 \\
\hline \multicolumn{7}{|c|}{ Panel B: long-run estimates } \\
\hline EPU & $-4.476^{* *}$ & 1.801 & -2.485 & & & \\
\hline $\mathrm{EPU}^{+}$ & & & & $3.216^{*}$ & 1.828 & 1.759 \\
\hline EPU & & & & $-1.461 * *$ & 0.621 & -2.353 \\
\hline ES & $-13.38 * * *$ & 2.486 & -5.385 & $-14.46 * * *$ & 3.035 & -4.766 \\
\hline FD & 7.729 & 14.162 & 0.546 & -10.22 & 14.06 & -0.727 \\
\hline FDI & $4.571 * * *$ & 1.754 & -2.607 & $2.457 * *$ & 1.172 & -2.096 \\
\hline $\mathrm{C}$ & 10.92 & 6.772 & 1.611 & $8.704 * *$ & 2.797 & 3.112 \\
\hline \multicolumn{7}{|c|}{ Panel C: diagnostic tests } \\
\hline$F$ test & $6.322 * *$ & & & $4.367 * *$ & & \\
\hline ECM & $-0.553 * *$ & 0.273 & 2.026 & $-0.706^{*}$ & 0.411 & 1.717 \\
\hline LM test & 1.781 & & & 2.702 & & \\
\hline BP test & 1.745 & & & 0.665 & & \\
\hline RESET & 0.995 & & & 1.235 & & \\
\hline \multicolumn{7}{|l|}{$\operatorname{Adj}-R^{2}$} \\
\hline CUSUM & $\mathrm{S}$ & & & $\mathrm{S}$ & & \\
\hline CUSUM squares & $\mathrm{S}$ & & & $\mathrm{S}$ & & \\
\hline WALD SR-EPU & & & & $4.568 * *$ & & \\
\hline WALD LR-EPU & & & & $5.368 * *$ & & \\
\hline
\end{tabular}

Notes:

${ }^{\text {a }} F$ tests level of significance is 4.15 at $10 \%$ and 5.01 at $5 \%$

${ }^{\mathrm{b}} \mathrm{LM}, \mathrm{BP}, \mathrm{RESET}$, and Wald tests are distributed at $\chi^{2}$ with the one degree of freedom and level of significance $2.71(3.84)$ at $10 \%(5 \%)$

$*, * *$, and $* * *$ reflect the significance level of $10 \%, 5 \%$, and $1 \%$ respectively autocorrelation and heteroskedasticity, while our model is correctly specified. This ECM result displays that the deviation of short-run to long-run equilibrium is $70.3 \%$ per year in nonlinear model and stability of parameters is also representing through CUSUM and CUSUM squares, which is stable. The results also indicate the short and long-term asymmetries in Wald statistics. Finally adjusted $R$-square has also revealed the goodness of fit in asymmetric models. 
Table 3 shows the linear and nonlinear causality outcomes, and the symmetric estimate shows one-way causality running from EPU to renewable energy consumption. Findings infer that economic policy uncertainty is significantly raised renewable energy consumption in China. This is finding is consistent with past literature and documented by Adedoyin and Zakari (2020). Renewable energy consumption does not Granger cause to EPU in symmetric causality. This is an addition to the empirical literature. The positive change in EPU is Granger caused by renewable energy use in China and consistent with symmetric causality. Financial development does not cause renewable energy consumption in China.

\section{Conclusion and policy implication}

This study inspects the impact of economic policy uncertainty on renewable energy consumption by carrying out NARDL methodology for China by data span from 1990-2019. Symmetric ARDL results suggest that economic policy uncertainty fosters renewable energy consumption in the short term as $1 \%$ upsurge in EPU raises renewable energy consumption

Table. 3 Results of symmetric and asymmetric causality test in China

\begin{tabular}{|c|c|c|c|c|c|}
\hline \multicolumn{3}{|c|}{ Symmetric causality } & \multicolumn{3}{|c|}{ Asymmetric causality } \\
\hline Null hypothesis & $\begin{array}{l}F- \\
\text { Stat }\end{array}$ & Prob. & Null hypothesis & $\begin{array}{l}F- \\
\text { Stat }\end{array}$ & Prob. \\
\hline $\mathrm{EPU} \rightarrow \mathrm{REC}$ & 2.607 & 0.096 & $\mathrm{EPU} \rightarrow \mathrm{REC}$ & 6.227 & 0.008 \\
\hline $\mathrm{REC} \rightarrow \mathrm{EPU}$ & 0.011 & 0.989 & $\mathrm{REC} \rightarrow \mathrm{EPU}^{-}$ & 0.042 & 0.959 \\
\hline $\mathrm{FD} \rightarrow \mathrm{REC}$ & 2.871 & 0.078 & $\mathrm{EPU}^{+} \rightarrow \mathrm{REC}$ & 1.747 & 0.199 \\
\hline $\mathrm{REC} \rightarrow \mathrm{FD}$ & 3.517 & 0.047 & $\mathrm{REC} \rightarrow \mathrm{EPU}^{+}$ & 2.729 & 0.088 \\
\hline FDI $\rightarrow$ REC & 0.315 & 0.733 & $\mathrm{EPU}^{+} \rightarrow \mathrm{EPU}^{-}$ & 1.222 & 0.315 \\
\hline $\mathrm{REC} \rightarrow \mathrm{FDI}$ & 4.479 & 0.023 & $\mathrm{EPU}^{-} \rightarrow \mathrm{EPU}^{+}$ & 0.921 & 0.414 \\
\hline $\mathrm{ES} \rightarrow \mathrm{REC}$ & 0.724 & 0.496 & $\mathrm{EPU} \rightarrow \mathrm{EPU}^{-}$ & 1.222 & 0.315 \\
\hline $\mathrm{REC} \rightarrow \mathrm{ES}$ & 5.681 & 0.01 & $\mathrm{EPU} \rightarrow \mathrm{EPU}$ & 0.423 & 0.661 \\
\hline $\mathrm{FD} \rightarrow \mathrm{EPU}$ & 0.366 & 0.697 & $\mathrm{FD} \rightarrow \mathrm{EPU}^{-}$ & 1.265 & 0.303 \\
\hline $\mathrm{EPU} \rightarrow \mathrm{FD}$ & 0.031 & 0.971 & $\mathrm{EPU} \rightarrow \mathrm{FD}$ & 0.439 & 0.651 \\
\hline $\mathrm{FDI} \rightarrow \mathrm{EPU}$ & 0.061 & 0.942 & $\mathrm{FDI} \rightarrow \mathrm{EPU}^{-}$ & 0.818 & 0.455 \\
\hline $\mathrm{EPU} \rightarrow$ FDI & 0.841 & 0.445 & $\mathrm{EPU}^{-} \rightarrow \mathrm{FDI}$ & 4.241 & 0.028 \\
\hline $\mathrm{ES} \rightarrow \mathrm{EPU}$ & 0.303 & 0.742 & $\mathrm{ES} \rightarrow \mathrm{EPU}$ & 0.215 & 0.808 \\
\hline $\mathrm{EPU} \rightarrow \mathrm{ES}$ & 1.202 & 0.321 & $\mathrm{EPU}^{-} \rightarrow \mathrm{ES}$ & 2.762 & 0.086 \\
\hline $\mathrm{FDI} \rightarrow \mathrm{FD}$ & 3.375 & 0.053 & $\mathrm{EPU} \rightarrow \mathrm{EPU}^{+}$ & 0.921 & 0.414 \\
\hline $\mathrm{FD} \rightarrow \mathrm{FDI}$ & 7.995 & 0.003 & $\mathrm{EPU}^{+} \rightarrow \mathrm{EPU}$ & 0.423 & 0.661 \\
\hline $\mathrm{ES} \rightarrow \mathrm{FD}$ & 5.034 & 0.016 & $\mathrm{FD} \rightarrow \mathrm{EPU}^{+}$ & 0.861 & 0.437 \\
\hline $\mathrm{FD} \rightarrow \mathrm{ES}$ & 1.569 & 0.231 & $\mathrm{EPU}^{+} \rightarrow \mathrm{FD}$ & 1.468 & 0.253 \\
\hline $\mathrm{ES} \rightarrow \mathrm{FDI}$ & 8.454 & 0.002 & $\mathrm{FDI} \rightarrow \mathrm{EPU}^{+}$ & 0.076 & 0.927 \\
\hline \multirow[t]{3}{*}{ FDI $\rightarrow$ ES } & 3.536 & 0.047 & $\mathrm{EPU}^{+} \rightarrow \mathrm{FDI}$ & 7.541 & 0.003 \\
\hline & & & $\mathrm{ES} \rightarrow \mathrm{EPU}^{+}$ & 1.235 & 0.311 \\
\hline & & & $\mathrm{EPU}^{+} \rightarrow \mathrm{ES}$ & 3.423 & 0.052 \\
\hline
\end{tabular}

by $0.950 \%$, whereas this effect is $4.476 \%$ negative significant on renewable energy consumption in the long run. Our asymmetric results in long and short run have deviated from the symmetric results. Therefore, asymmetric empirical outcomes indicate that positive change in economic policy uncertainty has significant and positive impacts on renewable energy consumption while the opposite is the case in the short and long run as negative change in economic policy uncertainty shows negative effects on renewable energy consumption. This infers that positive change in economic policy uncertainty minimizes the level of conventional energy and fosters creativity in the renewable energy market. These outcomes are consistent with Pirgaip and Dinçergök, 2020), who noted that EPU should be given attention as a dynamic that causes renewable energy consumption in different ways. These findings are important for academia and policymakers in the energy market and useful for real analysis.

Regarding control variables, economic size has negative and significant impact on renewable energy consumption in long run, while this effect is adverse in short run in ARDL and NARDL. However, FDI has a positive influence on renewable energy consumption in long term and paying a signifying role in clean energy consumption in China. Regarding asymmetric causality, a uni-directional causality runs from negative shock of economic policy uncertainty to renewable energy consumption and renewable energy consumption to positive shock of economic policy uncertainty in China. Financial development does not cause renewable energy consumption in China.

These empirical findings have some robust policy implications as they underscore the importance of policymakers, governments, consumers, and producers to maintain uniformity in economic and political policies to increase renewable energy consumption in China. China should place more attention on renewable energy consumption under high economic uncertainty. The Chinese authorities must deploy additional funds from foreign and domestic investors in the renewable energy market. Also, local and foreign investors can be inspired to renewable energy projects by donating funds. The Chinese government should retain the consistency of economic policies especially clean energy policies based on the full concern for the environment. Maintaining stable economic policies, especially policies in the energy market, could encourage the realization of carbon emission reduction targets. The empirical findings call for vital changes in clean energy policies to accommodate economic policy uncertainties. Economic policies must be linear and dynamic in the nature of consequences. Government authorities must prioritize their aims in policies for a healthy environment along with green economic activities.

The study focuses on one dimension of uncertainty due to the non-availability of data. Future studies should also consider political uncertainty in the analysis. We leave this prospect 
for future empirical studies. Another possible direction for future study could be to examine the relationship between financial deepening, political uncertainty, and renewable energy consumption in other regions of the globe.

Author contribution This idea was given by Wang Lei and Lihan Liu. Wang Lei, Lihan Liu, Muhammad Hafeez, and Sidra Sohail have collected the data, done empirical analysis, and written the complete paper. Muhammad Hafeez and Lihan Liu read and approved the final version.

Funding This study is sponsored by Beijing Wuzi University Youth Project No. 2019XJQN08

Data availability The datasets used and/or analyzed during the current study are available from the corresponding author on reasonable request.

\section{Declarations}

Ethics approval Not applicable.

Consent to participate I am free to contact any of the people involved in the research to seek further clarification and information.

Consent for publication Not applicable.

Competing interests The authors declare no competing interests.

\section{References}

Abbasi KR, Adedoyin FF (2021) Do energy use and economic policy uncertainty affect $\mathrm{CO} 2$ emissions in China? Empirical evidence from the dynamic ARDL simulation approach. Environ Sci Pollut Res: $1-13$

Adams S, Adedoyin F, Olaniran E, Bekun FV (2020) Energy consumption, economic policy uncertainty and carbon emissions; causality evidence from resource rich economies. Economic Analysis and Policy 68:179-190

Adedoyin FF, Zakari A (2020) Energy consumption, economic expansion, and $\mathrm{CO} 2$ emission in the UK: the role of economic policy uncertainty. Sci Total Environ 738:140014

Al-Thaqeb SA, Algharabali BG (2019) Economic policy uncertainty: a literature review. The Journal of Economic Asymmetries 20:e00133

Anton SG, Nucu AEA (2020) The effect of financial development on renewable energy consumption. A panel data approach. Renew Energy 147:330-338

Appiah-Otoo I (2020) Does COVID-19 affect domestic credit? Aggregate and bank level evidence from China. Asian Economics Letters 1(3): 1-5

Baker S, Bloom N, Davis S (2013) Measuring economic policy uncertainty. Stanford University and University of Chicago Booth School of Business.

Baker SR, Bloom N, Davis SJ (2016) Measuring economic policy uncertainty. Q J Econ 131(4):1593-1636

Balcilar M, Demirer R, Hammoudeh S (2019) Quantile relationship between oil and stock returns: Evidence from emerging and frontier stock markets. Energy Policy 134

Baloch MA, Ozturk I, Bekun FV, Khan D (2021) Modeling the dynamic linkage between financial development, energy innovation, and environmental quality: does globalization matter? Bus Strateg Environ 30(1):176-184

Bernanke BS (1983) Irreversibility, uncertainty, and cyclical investment. Q J Econ 98(1):85-106

Bhagat S, Ghosh P, Rangan SP (2013) Economic policy uncertainty and economic growth in India

Bloom N (2009) The impact of uncertainty shocks. Econometrica 77(3): $623-685$

Bourcet C (2020) Empirical determinants of renewable energy deployment: A systematic literature review. Energy Econ 85

Chen J, Zhou C, Wang S, Li S (2018) Impacts of energy consumption structure, energy intensity, economic growth, urbanization on PM2.5 concentrations in countries globally. Appl Energy 230:94 105

Chen L, Kettunen J (2017) Is certainty in carbon policy better than uncertainty? Eur J Oper Res 258(1):230-243

Ergun SJ, Owusu PA, Rivas MF (2019) Determinants of renewable energy consumption in Africa. Environ Sci Pollut Res 26(15):15390 15405

Gong H, Leigh A, Meng X (2012) Intergenerational income mobility in urban China. Rev Income Wealth 58(3):481-503

Gustafsson B, Shi L (2003) The ethnic minority-majority income gap in rural China during transition. Econ Dev Cult Change 51(4):805-822

Hailemariam WG, Silalertruksa T, Gheewala SH, Jakrawatana N (2019) Water-energy-food nexus of sugarcane production in Ethiopia. Environ Eng Sci 36(7):798-807

Hamilton SF (1983) The social side of schooling: ecological studies of classrooms and schools. Elem Sch J 83(4):313-334

Hatemi-j A (2012) Asymmetric causality tests with an application. Empir Econ 43(1):447-456

$\mathrm{Hu} \mathrm{C}$, Zhang L, Gong J (2019) Recent progress made in the mechanism comprehension and design of electrocatalysts for alkaline water splitting. Energy Environ Sci 12(9):2620-2645

Iyke BN (2020) COVID-19: The reaction of US oil and gas producers to the pandemic. Energy Research Letters 1(2):13912

Ji Q, Zhang D, Geng JB (2018) Information linkage, dynamic spillovers in prices and volatility between the carbon and energy markets. J Clean Prod 198:972-978

Joëts M (2015) Heterogeneous beliefs, regret, and uncertainty: The role of speculation in energy price dynamics. Eur J Oper Res 247(1):204 215

Joshua U, Bekun FV (2020) The path to achieving environmental sustainability in South Africa: the role of coal consumption, economic expansion, pollutant emission, and total natural resources rent. Environ Sci Pollut Res 27(9):9435-9443

Junttila J, Vataja J (2018) Economic policy uncertainty effects for forecasting future real economic activity. Econ Syst 42(4):569-583

Kang W, Ratti RA (2013) Oil shocks, policy uncertainty and stock market return. J Int Financial Mark Inst Money 26:305-318

Lafforgue G (2005) Uncertainty and amenity values in renewable resource economics. Environ Resour Econ 31(3):369-383

Li H, Lin J, Zhao Y, Kang JN (2019) Identifying the driving factors of energy-water nexus in Beijing from both economy-and sector-wide perspectives. J Clean Prod 235:1450-146

Lin C, He L, Yang G (2020) Targeted monetary policy and financing constraints of Chinese small businesses. Small Bus Econ 1-18

Liu JL, Ma CQ, Ren YS, Zhao XW (2020) Do real output and renewable energy consumption affect $\mathrm{CO} 2$ emissions? Evidence for selected BRICS countries. Energies 13(4):960

Liu R, He L, Liang X, Yang X, Xia Y (2020) Is there any difference in the impact of economic policy uncertainty on the investment of traditional and renewable energy enterprises?-A comparative study based on regulatory effects. J Clean Prod 255:120102

Liu Y, Han L, Yin L (2018) Does news uncertainty matter for commodity futures markets? Heterogeneity in energy and non-energy sectors. J Futures Mark 38(10):1246-1261 
Lundgren RE, McMakin AH (2018) Risk communication: A handbook for communicating environmental, safety, and health risks. John Wiley \& Sons, New York

Ma J, Wang J, Shen X (2021) Economic policy uncertainty and green economy efficiency: power or resistance?-Empirical evidence from Chinese major urban agglomerations. Econ Res-Ekon Istraz 1-19

Murshed M (2020a) An empirical analysis of the non-linear impacts of ICT-trade openness on renewable energy transition, energy efficiency, clean cooking fuel access and environmental sustainability in South Asia. Environ Sci Pollut Res 27(29):36254-36281

Murshed M (2020b) Are Trade Liberalization policies aligned with renewable energy transition in low and middle income countries? An instrumental variable approach. Renew Energy 151:1110-1123

Murshed M, Alam MS (2021) Estimating the macroeconomic determinants of total, renewable, and non-renewable energy demands in Bangladesh: the role of technological innovations. Environ Sci Pollut Res:1-21

Murshed M, Chadni MH, Ferdaus J (2020) Does ICT trade facilitate renewable energy transition and environmental sustainability? Evidence from Bangladesh, India, Pakistan, Sri Lanka, Nepal and Maldives. Energy, Ecology and Environment 5(6):470-495

Omri A, Nguyen DK (2014) On the determinants of renewable energy consumption: international evidence. Energy 72:554-560

Pindyck RS, Rubinfeld DL (1991) Models of qualitative choice. Econometric Models, Economic Forecasts 273-315

Pirgaip B, Dinçergök B (2020) Economic policy uncertainty, energy consumption and carbon emissions in G7 countries: evidence from a panel Granger causality analysis. Environ Sci Pollut Res Int 27: 30050-30066

Reboredo JC, Wen X (2015) Are China's new energy stock prices driven by new energy policies? Renew Sustain Energy Rev 45:624-636

Rehman A, Deyuan Z (2018) Pakistan's energy scenario: a forecast of commercial energy consumption and supply from different sources through 2030. Energy Sustain Soc 8(1):1-5

Sadorsky P (2011) Financial development and energy consumption in Central and Eastern European frontier economies. Energy Policy 39(2):999-1006
Shafiullah M, Miah MD, Alam MS, Atif M (2021) Does economic policy uncertainty affect renewable energy consumption? Renew Energy 179:1500-1521

Sharif A, Baris-Tuzemen O, Uzuner G, Ozturk I, Sinha A (2020) Revisiting the role of renewable and non-renewable energy consumption on Turkey's ecological footprint: evidence from quantile ARDL approach. Sustain Cities Soc 57:102138

Shin Y, Yu B, Greenwood-Nimmo M (2014) Modelling asymmetric cointegration and dynamic multipliers in a nonlinear ARDL framework. In: In Festschrift in honor of Peter Schmidt. Springer, New York, NY, pp 281-314

Sohail MT, Xiuyuan Y, Usman A, Majeed MT, Ullah S (2021) Renewable energy and non-renewable energy consumption: Assessing the asymmetric role of monetary policy uncertainty in energy consumption. Environ Sci Pollut Res 1-10

Toda HY, Yamamoto T (1995) Statistical inference in vector autoregressions with possibly integrated processes. J Econ 66(1-2): 225-250

World Bank (2019) World development indicators 2019. World Bank Publications

Wu J, Li H, Zheng D, Liu X (2021) Economic uncertainty or financial uncertainty? An empirical analysis of bank risk-taking in Asian emerging markets. Finance Res Lett 39:101542

Yu J, Shi X, Guo D, Yang L (2021) Economic policy uncertainty (EPU) and firm carbon emissions: evidence using a China provincial EPU index. Energy Econ 94:105071

Zhang D, Lei L, Ji Q, Kutan AM (2019) Economic policy uncertainty in the US and China and their impact on the global markets. Econ Model 79:47-56

Zhang H, Zhang S, Liu S, Wang Y, Lin L (2015) Measurement and analysis of friction and dynamic characteristics of PIG's sealing disc passing through girth weld in oil and gas pipeline. Measurement 64: $112-122$

Publisher's note Springer Nature remains neutral with regard to jurisdictional claims in published maps and institutional affiliations. 